\title{
Modelagem Fuzzy na identificação de Fraude no Mercado de Seguro de Automóveis
}

\author{
Lucas Pereira Lopes \\ Instituto de Ciências Sociais Aplicadas, UNIFAL-MG, Varginha, MG. \\ Richard Hernani Pereira ${ }^{2}$ \\ Instituto de Ciências Sociais Aplicadas, UNIFAL-MG, Varginha, MG
}

Resumo. Com o avanço da matemática e da estatística, muitos métodos foram desenvolvidos para trabalhar dentro da ciência atuarial, todavia, ainda carece de estruturas matemáticas que se adaptem ao tratamento de incertezas não estatísticas. Assim, com essa característica, a lógica fuzzy se apresenta como uma teoria adequada para lidar com alguns assuntos da Ciência Atuarial.

Kaufmann e Gupta (1988) argumentam que os modelos clássicos, apesar de funcionarem bem nos fenômenos simples e isolados, não são suficientemente adequados para tratar dos problemas contemporâneos e de suas complexidades, interações e subjetividades humanas. As ferramentas matemáticas determinísticas e probabilísticas têm sido desenvolvidas com base nas teorias convencionais de sistemas que obedecem a regras e variáveis bem definidas, como nos sistemas da Física.

Gigch e Pipino (1980) mostram que nos conjuntos fuzzy, "os conceitos de sim ou não, bom ou ruim, verdadeiro ou falso e preto e branco são substituídos por conceitos onde existem tanto as verdades parciais quanto as falsidades parciais". Essa simples diferenciação, na verdade capta a essência da teoria da lógica fuzzy.

Um dos ramos da Ciência Atuarial é o estudo de seguro. Na década de 80 do século passado, o segmento de seguros automobilísticos no Brasil representava cerca de $1 \%$ a $2 \%$ do PIB brasileiro, hoje, está entre $3 \%$ e $4 \%$. Com o crescimento econômico do País, o mercado de seguros acompanhou o mesmo, fazendo com que as seguradoras sejam responsáveis por uma grande parcela da frota automobilística do Brasil. Com um número crescente de segurados, um problema que está aumentando é a fraude, onde o segurado tenta burlar o sistema para ter um beneficio financeiro. No mundo inteiro o fenômeno das fraudes em seguros é considerado um problema relevante e extremamente atual. Nos EUA algumas estimativas o indicam como o segundo maior crime financeiro, atrás somente da evasão fiscal. No Brasil a situação está longe de ser claramente definida. A Fenaseg desenvolveu em 2006 um estudo abrangente sobre o assunto, baseado nos dados de 2005. Com base neste estudo

\footnotetext{
${ }^{1}$ luccas.lopes@live.com

2 richard.hernani@gmail.com
} 
chegaram a uma estimativa de 11,6\% de fraudes (ou cerca de 1,45 bilhões de Reais), calculado como percentual dos sinistros pagos no conjunto de ramos de seguros, excluindo os setores de saúde e previdência.

Neste trabalho é proposto um sistema baseado em regras fuzzy para identificar quando um pedido de indenização possa ser considerado suspeito ou não, sendo o histórico do seguro, histórico bancário e avaliação pessoal, as três variáveis de entrada do sistema. Uma das justificativas deste trabalho é fornecer uma nova ferramenta para a detecção de fraude, pois a mesma auxiliaria na rapidez e eficácia das seguradoras. Um sistema baseado em regras fuzzy é válido por utilizar figuras de linguagem e então demonstrar relações que podem ser complexas ou são insuficientemente entendidas para serem descritas em modelos matemáticos clássicos. Foi elaborada uma base de regras do tipo: "Se a história do seguro for ruim, o histórico bancário for bom e a avaliação pessoal for péssima, então o pedido é suspeito". Utilizouse o método de inferência de Mandami. Tal modelo fornece um valor entre 0 a 1 que permite a seguradora ter base para decidir se um pedido de indenização tem natureza fraudulenta ou não. Tendo como base um valor limitante para a sua tomada de decisão.

O papel do especialista em seguros foi de suma importância para a formulação das regras. Uma restrição até agora não solucionada foi à utilização de dados reais, portanto, todo o trabalho foi gerado com simulações de dados.

Apesar do resultado do modelo de identificação de fraude ser subjetivo para cada seguradora, pelos resultados é possível tomar decisões administrativas utilizando o modelo proposto. Com a utilização de um sistema baseado em regras fuzzy, viu-se a potencialidade de tal teoria ao modelar um problema de dados qualitativos.

Palavras-chave. Fraude em Seguro, Sistema Fuzzy, Base de regras.

\section{Agradecimentos}

Aos professores do Instituto de Ciências Sociais Aplicadas da Universidade Federal de Alfenas-MG e à equipe da SBMAC pela oportunidade.

\section{Referências}

[1] A. Kaufmann and M. Gupta, Introduction to Fuzz Arithmetic, New York: Van Norstrand Reinhold Company, (1985).

[2] J. Gigh and L Pipino, Form Absolute to Probable to Fuzzy in Decision Making, Kybernetes, v. 09, p. 47-55, (1980). 